\title{
XVIII. Supplementary remarks relative to certain arguments against the theory of molecular action according to Newton's law
}

Rev. P. Kelland M.A. F.R.SS.L.\&E. F.C.P.S.

To cite this article: Rev. P. Kelland M.A. F.R.SS.L.\&E. F.C.P.S. (1843) XVIII. Supplementary remarks relative to certain arguments against the theory of molecular action according to Newton's law, Philosophical Magazine Series 3, 22:143, 116-120, DOI: 10.1080/14786444308636333

To link to this article: http://dx.doi.org/10.1080/14786444308636333

曲 Published online: 01 Jun 2009.

Submit your article to this journal $[\pi$

Џll Article views: 2

Q View related articles $\sqsubset$ 


\section{Prof. Kelland's Supplementary Remarks on certain}

chromic vision, which seem so puzzling when related, cease to be matter of any surprise *.

[To be continued.]

XVIII. Supplementary Remarlss relative to cerlain Arguments against the Theory of Molecular Action according to Newton's Law. By the Rev. P. Kelland, M.A.,F.R.SS.L.\& E., F.C.P.S., \&c., Professor of Mathematics in the University of Edinburgh, late Fellow and Tutor of Queen's College, Cambridge.

BEING called upon by Mr. Earnshaw in the Number of the Philosophical Magazine for December (S. 3. vol. xxi, p. 444.) to reply directly to a series of categorical questions, and being at the same time desirous of keeping the discussion as simple and disentangled as possible, I trust I may be allowed the benefit of an early insertion of the following remarks, as proper to precede anything which either party may add to the controversy. I believe we are all agreed in desiring that this point should be cleared up as a preliminary step. I will therefore, for the present, confine myself exclusively to it. The matter in question resolves itself into the answers to the following queries.

1. Does it follow from the hypothesis which I have adopted that the three following expressions are equal, -

$$
\begin{aligned}
& 2 \Sigma\left(\phi r+\frac{\mathrm{Fr}}{r} \delta x^{2}\right) \sin ^{2} \frac{k \delta \rho}{2}, \\
& 2 \Sigma\left(\phi r+\frac{\mathrm{Fr}}{r} \delta y^{2}\right) \sin ^{2} \frac{k \delta \rho}{2}, \\
& 2 \Sigma\left(\phi r+\frac{\mathrm{Fr}}{r} \delta z^{2}\right) \sin ^{2} \frac{k \delta \rho}{2},
\end{aligned}
$$

they being the proportions of force to disturbance, parallel respectively to $x, y$, and $z$ ? On the assumption of their equality depend the arguments adduced at pp. 341 and 343 of the Philosophical Magazine for November, by my respective opponents.

* The late celebrated optician Mr. Troughton, who was a remarkable instance of this sort of vision, informed me that he could not distinguish the scarlet coats of a regiment of soldiers from the green turf on which they were drawn up, nor ripe cherries from the leaves of the tree which bore them. His eyes, however, were perfectly sensible to rays of every refrangibility as light, but the spectrum afforded him only the sensations of two colours, which he termed blue and yellow; pure red and pure yellow rays exciting in his mind the same sensation. [See a paper by the late Mr. G. Harvey on an anomalous case of vision, reprinted from the Transactions of the Royal Society of Edinburgh, in Phil. Mag., S. 1. vol. lxviii, p. 205,-Evrт.] 
2. Does it follow from the arguments I have used that they ought to be equal?

3. Do I make an axis of coordinates to coincide with the direction of transmission?

1. I say it does not follow from any hypothesis that these quantities should be equal; nor even that the equations should assume the form assigned to them at p. 162, unless one of the axes of coordinates be that of transmission. This I suppose my opponents will admit, at least Mr. O'Brien himself points out the fact, when he says (Phil. Mag. for June, 1842, p. 485), "I assert that the equations at the foot of p. 162 of the Transactions of the Camb. Phil. Soc. are essentially erroneous; they ought to have been in the form," \&c. He explains himself afterwards, (Phil. Mag. for November, p. 345, P.S.) by making me exclude the case (the only one I did not exclude) in which an axis of coordinates coincides with the direction of transmission. Mr. O'Brien then admits (what is quite correct) that even the form of the equations, to say nothing of the equality of the quantities themselves, is not a necessary consequence of the hypothesis of molecular forces. I may add that the true form corresponding with the case supposed by $\mathrm{Mr}$. O'Brien, will be found in the Transactions of the Camb. Phil. Soc. p. 331. Any arguments, then, levelled at the Newtonian Law through the supposed equality of these quantities, fall to the ground.

2. But does it follow from the arguments $I$ have used that they ought to be equal? If it does, no consequences will follow, except the obvious one, that $I$ have committed an error in one proposition. But this clearly does not follow from my arguments. The quantities are doubtless denoted by the same letter $n$; and Cauchy designates them by the same letter $s$, almost always. At p. 139 of the Exercices d'Analyse, we find $s^{2}=\mathbf{E}, s^{2}=\mathbf{E}+\mathbf{F} k^{2}$, the one directly. under the other. But it may be urged that $I$ have myself apparently sanctioned the supposition that the quantities are equal, by what I say at p. 163. I have already twice over admitted that some little confusion appears in this place. But if this be insufficient, I think the right way to determine whether I did consider the quantities to be equal or not, is to turn to where I have applied them. It will be found that, far from supposing this to be the case, I have proved them to be unequal. Let me point out where. In the Trans. of the Camb. Phil. Soc. pp. 179180 , and p. 268 , for $v$ differs from $n$ only by a constant multiplier: in the Philosophical Magazine for May, 1837, p. 340, and in my Theory of Heat, p. 155 . I assert, moreover, that I have never treated the three quantities as equal-if I have, let my opponents say where. 


\section{Prof. Kelland's Supplementary Remarks on certain}

3. Do I not make an axis of coordinates to coincide with the direction of transmission? On this depends the correctness of my equations. Their very form is determined by the fact that I do. It has been shown above that they assume an essentially different form in the contrary case.

At p. 161, I say " ... we might at once suppose the direction of transmission to be the axis of $y$, and put $\delta y$ for $\delta \rho$; this, however, I shall not do, as it does not appear necessary, and it is convenient to retain the symbol $\rho$, on other accounts to be noticed hereafter. The above remarks will be mainly useful in pointing out to us what are the quantities to be rejected in our equations of motion." I refer to this when I say (p. 162) "bearing in mind the remark above made with respect to $\rho . "$ Now I am quite sensible this might have been better and more clearly stated. But the reason why I did not put the symbol $y$ for $\rho$, or rather why I changed $y$ into $\rho$, as I actually did, was this: I wished to retain a symbol which might be converted into $x, y$, or $z$ at pleasure; and my readers will find I made $\rho$ to represent in succession $x$ and $z$ at p. 166, and $y$ at p. 179. I will add further, that I never changed it into anything else. I never supposed it to incline to the axes. But the most satisfactory way of ascertaining how I understood my equations, will be to inquire how I interpreted and used them. I assert-always as having an axis of coordinates along the axis of transmission. Let my opponents point out one place in all my writings where $\tilde{I}$ have done otherwise. It would be tedious for me to go over all I have written, and extract every passage where the form occurs. It will suffice that I point out a few. Trans. Camb. Phil. Soc. vol. vi. pp. 179, 239, 245, \&c.; Phil. Mag. for May, 1837, p. 336; Theory of Heat, p. 146. In all these places, and in every other in which these equations occur, the direction of transmission coincides with one of the axes of coordinates.

I proceed, now, in conclusion, to answer Mr. Earnshaw's questions at p. 444 of the Magazine for this month (Dec.), or rather to answer one of them, so as to render the rest nugatory.

1. "Does Professor Kelland admit that I have satisfactorily proved that the quantity $n$ used in his memoir on dispersion, is equal to zero?"

I answer No. And wherefore? Because the proof rests on the assumption that three quantities are equal, which are essentially and necessarily not so. One of them must be different from the others. If any one thinks otherwise, let him prove that they are equal, or let him point out an error in my proof of their inequality.

Edinburgh, December 6, 1842 . 
P.S. Should any of my readers be desirous of seeing a proof of the inequality of the three expressions, elsewhere than in my own writings, they will find it at p. 301 of the Exercices $d^{\prime}$ Analyse of M. Cauchy. In a paper, part of which is already in the hands of the Editor, $I$ have proved that my equations give rise, by the most simple process, to $M$. Cauchy's results. This is a sufficient guarantee for their correctness, and a strong illustration of the importance of the method which I have adopted.

P.S. Jan. 4, 1843.-The Philosophical Magazine for this month, with the united reply of Mr. Earnshaw and $\mathrm{Mr}$. O'Brien, has just reached me. . The object of the arguments in that paper is to show that what I termed a misprint or mistranscription, is in reality a mistake. Now suppose I grant them this for the sake of getting along, what do they gain by it? Do I thereby "confess that my fundamental equations are essentially erroneous" (O'Brien, p. 22)? No such thing. I confess no more than this-that there is an error in the equations, which error has never been propagated to other parts of my writings, and which has been corrected by myself in the Philosophical Magazine for May 1837. If then these gentlemen choose to call it a mistake, let them do so, and we will proceed to our arguments. But let not my readers be deceived by assertions. If this is an error in my fundamental equations, I again demand, where are these erroneous equations used by me? The case then stands between us as before. To follow their three positions:-1. I have never admitted the three $n$ 's as equal, although in the place in question they were denoted by the same letter. 2. I have never applied the equations without the limitation (relative to the direction of transmission) which they deem necessary. And 3. I have taken, and do still take, the blame of leading these gentlemen astray to myself.

In their P.S. is exhibited what is more tangible, an argument against the theory, and another against the consequences which I drew. They are, -1 , that because $v^{2}+v^{\prime 2}+v^{\prime \prime 2}=0$, $v=0, v^{\prime}=0, v^{\prime \prime}=0$. Every one is aware that there are two ways of satisfying these equations, viz. (1) by the method which they give, and (2) by supposing that one (or two) of the quantities is impossible. Now the first cannot be true, for the nature of the function $\Sigma m\left(\frac{1}{r^{3}}-\frac{3 \delta x^{2}}{r^{5}}\right) \sin ^{2} \frac{\pi \delta y}{\lambda}$ is such that in some cases it must depend on the relation of $\delta y$ to $\lambda$.

And further, M. Cauchy, in the place cited above, has determined the value of this function, and based an important 
argument on it against the Newtonian Law (Exercices d'Analyse, p. 304). But that the second solution is the true one, will appear from considering that it only changes a circular function into an exponential one, which will, in general, not appear in the operations from its coefficient being zero.

2. But we have an argument against the solution, or rather an assertion, that the appearance of an exponential in place of a circular function "violates the hypotheses on which the reductions and transformations in the former part" (I should like to know what part) "of my paper are effected." If they mean those in p. 158, and which they refer to, I reply, so does Neroton's problem of central forces violate his hypothesis of motion in an ellipse about the centre. But if these gentlemen assert that exponentials cannot be used for circular functions, and vice versá, I refer them to the memoir of Cauchy just quoted, where nothing but exponentials are used, and to my 'Theory of Heat,' p. 156. I may add that this objection is so vaguely and cautiously stated, that I do not imagine the writers seriously entertain any belief in its force, but rather throw it out as a probable difficulty.

XIX. On the Action of the Rays of the Solar Spectrum on the Daguerreotype Plate. By Sir J. F. W. Henschel, Bart., K.H., F.R.S., \&c.

To the Editor of the Philosophical Magazine and Journal. SIR,

1. PROFESSOR Draper of New York having, in his communication to the Philosophical Magazine for November last (Art. LXII.), referred to a specimen of a Daguerreotyped impression of the solar spectrum obtained by him in the south of Virginia as having been forwarded by him to me through your obliging intervention, I should hardly be doing justice, either to his urbanity or to the beauty of the specimen itself as a joint work of nature and art, were I to forbear acknowledging its arrival and offering a few remarks on it. And I do so the more readily, because, though forced to differ with him in some of the conclusions he has drawn from it, I recognize in him a zealous and effective contributor to this most interesting branch of scientific inquiry, and the only one, so far as I am aware, besides myself who has attacked it in the only mode in which it can lead to distinct and definite results, that of prismatic analysis.* It can never be too often repeated, that the use of coloured glasses

* Since this was written, M. Becquerel's interesting paper on the Spectrum, read to the French Academy, June 13, 1842, has come into my hands. M. Becquerel has also used the prism, and with excellent effect, 